\title{
Differences in aerosol flow rates between disposable and reusable atomizers used for airway topicalization: implications for local anesthetic toxicity
}

\author{
Haotian Wang, MD $\cdot$ R. Zachary Ford, BSc $\cdot$ Andrew D. Milne, MD, MSc
}

Received: 5 September 2020/Revised: 24 October 2020/ Accepted: 28 October 2020/Published online: 18 November 2020

(c) Canadian Anesthesiologists' Society 2020

\section{To the Editor,}

Awake flexible bronchoscopic intubation is one method used to manage a patient with a difficult airway. ${ }^{1,2}$ Topicalization of the airway with local anesthetic (LA) prior to awake tracheal intubation is important to blunt the gag and cough reflexes, thus minimizing patient discomfort. Modalities of LA delivery to the airway include liquid gargles, topical gels or pastes, targeted nerve injections, and atomization for inhalation. ${ }^{1,3}$ Careful consideration should be given to the cumulative LA dose administered with these modalities to reduce the risk of potential LA systemic toxicity. ${ }^{1,4}$ Our institution recently changed from reusable DeVilbiss atomizers (Model 15, DeVilbiss Healthcare, Somerset, PA, USA) to disposable atomizers (EZ-100 and EZ-100m, Alcove Medical, Lehi, UT, USA) to prevent cross-contamination between patients. The purpose of this study was to compare the simulated LA delivery flow rates between these atomizer devices.

Institutional ethics approval was not required for this bench-top equipment study. Standard E-cylinder oxygen

Presented in part at the Difficult Airway Society Meeting, London, England, 2017.

\section{H. Wang, MD $(\bowtie) \cdot R$. Z. Ford, BSc}

Department of Anesthesia, Pain Management and Perioperative

Medicine, Dalhousie University, Halifax, NS, Canada

e-mail: Haotian.Wang@dal.ca

A. D. Milne, MD, MSc

Department of Anesthesia, Pain Management and Perioperative

Medicine, Dalhousie University, Halifax, NS, Canada

School of Biomedical Engineering, Dalhousie University, Halifax, NS, Canada tanks were used as the carrying gas for atomization. Full tanks were used and replaced when half empty. Atomizer chambers were filled to their nominal capacity (DeVilbiss $20 \mathrm{~mL}$, EZ-100m $15 \mathrm{~mL}$, and EZ-100 $50 \mathrm{~mL}$ ) using a standard medical grade syringe. The time to empty each device under continuous discharge was recorded using a handheld stopwatch. To allow direct comparison between devices with different filling volumes, the aerosol flow rate was calculated (flow $=$ volume/time). To determine the effects of fluid type on delivery rate, a pilot trial was performed for each oxygen flow rate with liquid lidocaine (Lidodan ${ }^{\circledR} 4 \%$, Odan Laboratories Ltd, Montréal, QC, Canada) and then sterile water. There was no appreciable difference between the flow rates for $4 \%$ lidocaine and sterile water. Subsequently, five repeated trials were performed with six devices of each model type at seven different oxygen flow rates $\left(4-25 \mathrm{~L} \cdot \mathrm{min}^{-1}\right.$ ) using sterile water (i.e., simulated LA). The accuracy of portable oxygen tank flow meter settings were tested using a sample of six full oxygen tanks using a Puritan Bennett $^{\mathrm{TM}}$ ventilator flow tester.

Significant differences in the aerosol delivery flow rates were observed between all three atomizer models at all oxygen carrying gas flow settings (Figure). At a clinically relevant oxygen carrying gas flow setting of $8 \mathrm{~L} \cdot \mathrm{min}^{-1}$, we observed the EZ-100 and EZ-100m atomizers delivery flow rates were on average 2.4- and 1.9-fold higher than the DeVilbiss device, respectively. Testing the accuracy of oxygen tank delivery flow rates with a flow meter showed a mean flow error of $8 \%$ from the nominal tank flow gauge settings.

One limitation of this study is the variability of portable oxygen tanks as a carrying gas supply for atomization. Nevertheless, this represents typical clinical usage and wall oxygen supply lines have also been found to 

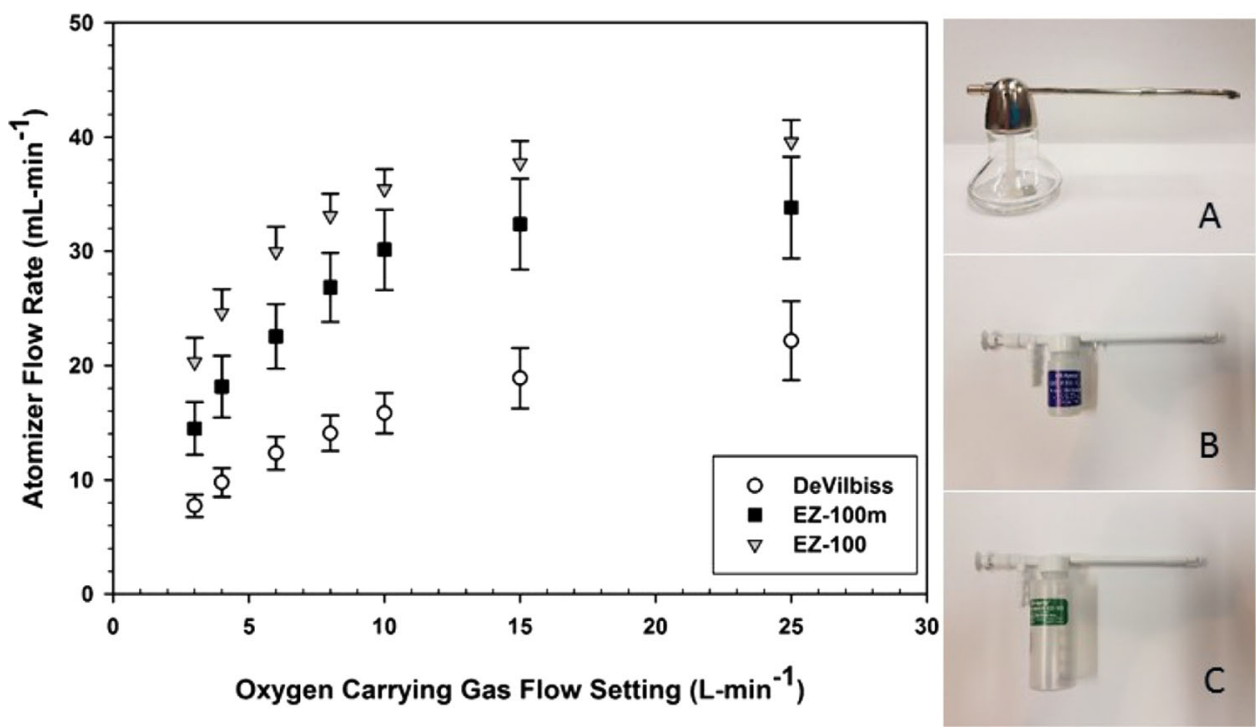

Figure Mean aerosol delivery flow rates (with 95\% confidence intervals as the error bars) for the DeVilbiss (A), EZ-100m (B), and EZ-100 atomizers (C). The atomizer flow rates were calculated by dividing the time to empty (measured using a stopwatch) by the device specific reservoir filling volumes (DeVilbiss $20 \mathrm{~mL}$, EZ-100m $15 \mathrm{~mL}$, and EZ-100 $50 \mathrm{~mL}$ ). A two factor analysis of variance (atomizer type, oxygen flow rate) with multiple pairwise comparisons using the Holm-Sidak method were used for statistical analysis. Both

be inaccurate. ${ }^{5}$ Another potential limitation is that we retested the disposable devices at multiple oxygen flow settings, which could potentially cause wear at the nozzle orifice and affect atomization flow rates. Moreover, we made no attempt to compare particle sizes between atomization devices.

In summary, the disposable EZ-100 and EZ-100m can deliver atomization at approximately twice the flow rate of the reusable DeVilbiss atomizer. In the clinical setting, use of the EZ-100 device with its higher aerosol delivery flow rate and larger $50-\mathrm{mL}$ reservoir could result in the unintentional administration of a large amount of LA by users accustomed to the older DeVilbiss type atomizers. To avoid potential LA systemic toxicity, we recommend limiting the total LA dose (less volume or lower concentration) in the reservoir. Use of the EZ-100m with its smaller chamber size $(15 \mathrm{~mL})$ may also help reduce the potential for inadvertent overdosing of LA.

Disclosures None.

Funding statement None. device type $(P<0.001)$ and oxygen carrying gas flow rate $(P<$ $0.001)$ were significant factors affecting atomizer flow rates. Pairwise comparisons showed significant differences in atomizer flow rates between all three atomizer models at all oxygen tank settings (HolmSidak tests, significance levels ranging from $P<0.001$ to $P=0.002$ ). The error bars for the EZ-100 data series are only shown in one direction for graphical clarity

Editorial responsibility This submission was handled by Dr. Hilary P. Grocott, Editor-in-Chief, Canadian Journal of Anesthesia.

\section{References}

1. Morris IR. Airway anesthesia techniques. In: Hung OR, Murphy MR, editors. Management in the Difficult and Failed Airway. NY: McGraw-Hill Medical; 2008. p. 47-53.

2. Law JA, Morris IR, Brousseau PA, de la Ronde S, Milne AD. The incidence, success rate, and complications of awake tracheal intubation in 1,554 patients over 12 years: an historical cohort study. Can J Anesth 2015; 62: 736-44.

3. Clark GD, Pond $C$. Adaptation of the de Vilbiss atomizer for the delivery of topical anesthesia. Nurse Anesth 1992; 3: 20-4.

4. Mehra P, Caiazzo A, Maloney P. Lidocaine toxicity. Anesth Prog 1998; 45: 38-41.

5. Davidson J, Gazzeta C, Torres LC, Jardim JR, Nascimento OA. Precision and accuracy of oxygen flow meters used at hospital settings. Respir Care 2012; 57: 1071-5.

Publisher's Note Springer Nature remains neutral with regard to jurisdictional claims in published maps and institutional affiliations. 